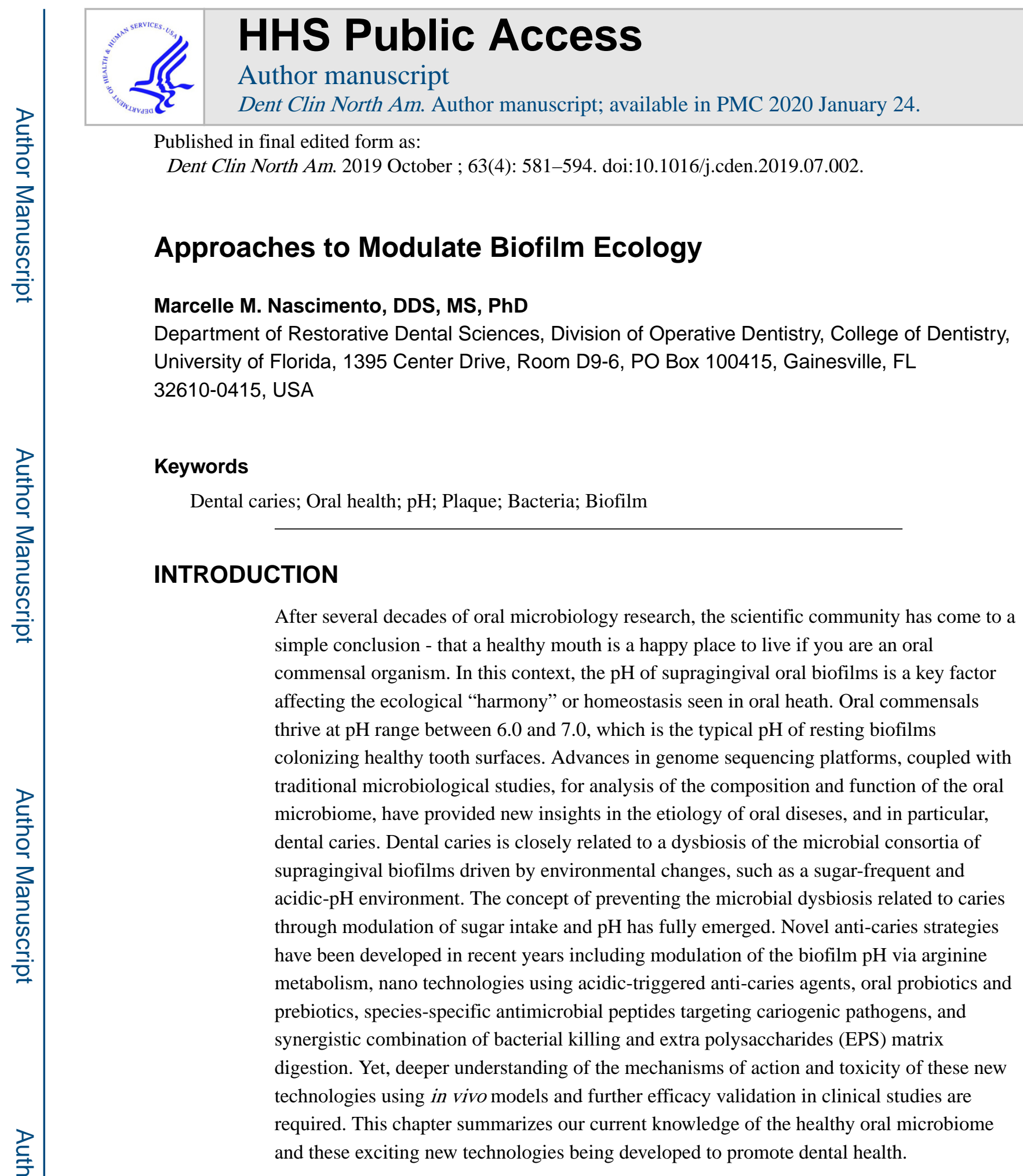

The oral microbial ecosystem plays an essential role in human health. This is because the oral cavity is a major portal of microbial entry to the human body, and the altered oral microbiota has been intimately associated with oral and systemic diseases. The potential link between oral diseases (eg, dental caries and severe periodontitis) (Figs. 1 and 2) and systemic diseases (eg, cardiovascular disease, rheumatoid arthritis, and diabetes) has prompted great interest in the oral microbiome. ${ }^{1,2}$ There is also an evolving trend for dental

mnascimento@dental.ufl.edu. 
and medical research to share knowledge on the etiology and pathogenicity of human diseases. ${ }^{3,4}$ Such interest follows insights provided from the Human Microbiome Project revealing that ecological balance in biofilms plays a significant role in health. ${ }^{4}$

Nowadays, ecologists and data scientists are beginning to collaborate with clinical scientists, and this teamwork is crucial to understand the potential of microbiome-informed and microbiome-based medicine and why not microbiome-based dentistry? Improvements in the throughput and accuracy of DNA sequencing of the genomes of microbial communities of human samples, accompanied by analysis of transcriptomes, proteomes, metabolomes, and immunomes, and by functional experiments, have vastly improved the ability to understand the structure and function of the microbiome associated with disease and health. Our understanding of the link between the oral and the human microbiome is rapidly expanding. In the era of applied meta-omics and personalized medicine, the oral microbiome is a valuable asset. ${ }^{5}$ The oral microbiome encompasses the ecological community of commensal, symbiotic, and pathogenic microorganisms that share the mouth space. ${ }^{6}$ This community forms a dynamic and complex microbial ecosystem that usually exists in homeostasis or symbiotic state with the host, such as that found in healthy-associated supragingival oral biofilms. $^{7}$

\section{THE ECOLOGICAL COMPLEXITY OF THE HUMAN MOUTH}

From the time of birth, the human mouth is a primary point of entry of microorganisms into the human body. ${ }^{6}$ Microorganisms in the air food and those that are transferred through oral fluids (mainly saliva) from family members, caregivers, and others, can either just pass through the mouth or they can colonize the several oral niches. In fact, the complex ecosystem of the mouth supports the growth of diverse microbial communities comprising bacteria, viruses, mycoplasmas, archaea, fungi and protozoa that coinhabit and functionally interact in oral biofilms. The environmental factors that make the mouth such an attractive place for microorganisms include the: moisture and warmth (35-37C), presence of a variety of microbial niches, and abundance and continual influx of nutrients for microbial growth, such as salivary proteins, glycoproteins, and dietary components such as carbohydrates. ${ }^{8,9}$ As a result, the human mouth is home to over 800 bacterial species organized into microbial communities that occupy multiple niches, including saliva, dental plaque, gingival crevice, and various soft tissue surfaces that compose the buccal mucosa and the tongue. ${ }^{6}$

The most abundant members of the oral microbiota are commensal organisms beneficial for oral health, but pathogens responsible for oral disease also exist. Commensal communities function to maintain the normal development of host tissues and defenses, by providing colonization resistance and down-regulation of damaging host inflammatory responses. However, the homeostasis or symbiotic relationship between the oral microbiome and the host is highly dynamic, as the composition and metabolic activities of microbial communities fluctuate according to the environmental changes in $\mathrm{pH}$, nutrient availability, oxygen tension and redox environment, shedding effects of oral surfaces, and composition of salivary and crevicular fluids. ${ }^{10}$ 
The $\mathrm{pH}$ and carbohydrate availability are key environmental factors affecting the physiology, ecology, and pathogenicity of the oral biofilms colonizing the teeth. ${ }^{11}$ Many beneficial oral bacteria can tolerate short periods of low $\mathrm{pH}$, but their growth is inhibited by prolonged or frequent exposures to acidic conditions. In this context, the buffering activity of saliva plays a major role in maintaining the intraoral $\mathrm{pH}$ at around neutrality, which is optimal for the growth of most members of the oral microbiome. ${ }^{12}$ Changes in environmental $\mathrm{pH}$ occur following consumption of dietary sugar. Specifically, organic acids produced by the fermentation of dietary carbohydrates by cariogenic bacteria elicit demineralization of tooth enamel. These periods of acid challenge to the tooth are followed by periods of alkalization, which neutralizes plaque $\mathrm{pH}$ and promotes remineralization of tooth enamel. ${ }^{11}$ Whereas many factors contribute to the alkalization of oral biofilms (eg, buffers in saliva or diffusion of acids out of biofilms), alkali generation by oral bacteria plays a major role in $\mathrm{pH}$ homeostasis in oral biofilms and inhibits the initiation and progression of dental caries. $11,13,14$

Oral microorganisms gain substantial advantages by growing as a biofilm, and by functioning as a microbial community. Biofilms are inherently more tolerant to environmental stresses, host defenses, and antimicrobial agents, compared with growth as single microbial cells. The complex spatial organization or biogeography of supragingival oral biofilms was demonstrated by spectral imaging fluorescence in situ hybridization (CLASI-FISH) and metagenomic sequence analysis. ${ }^{15}$ Corynebacterium was shown as the cornerstone of supragingival plaque architecture with long filaments that serve as anchor sites for many other microorganisms. ${ }^{15}$ This study also revealed that individual taxa are localized at the micron scale, in ways suggestive of their functional niche in the biofilm consortium. For example, anaerobic taxa tend to be in the interior, whereas facultative or obligate aerobes tend to be at the periphery of the consortium. Consumers and producers of certain metabolites such as lactate (the main acid dissolving tooth tissues) tend to be near each other.

The architecture of oral biofilms allows for synergetic and antagonistic interactions among different microbial species, and these interactions are central to homeostasis. Genome sequencing techniques have identified some of these oral microorganisms, but several others about one-third of oral bacteria - are yet to be isolated from oral samples and cultivated in the laboratory by using conventional microbiological methods. Bacterial cultivation of certain strains may be challenging, because of their specific requirements for nutrients, while others may be inhibited by substances in the culture media, or produced by other bacteria. ${ }^{16}$ However, recent progress has been made on cultivating or cocultivating the so-called uncultivable bacteria, and greater knowledge about the ecological role of these "hard-togrow bugs is being acquired.

\section{THE CARIES MICROBIOME}

The microbiome that naturally colonizes teeth in health is a biofilm community that can counterbalance acid production from dietary intake of carbohydrates to maintain an intact tooth surface (eg, by ammonia production from arginine or urea). ${ }^{11}$ As proposed by Marsh,

17 excessive and frequent intake of carbohydrates exceeds the buffering capacity of the 
healthy microbiome and leads to dysbiosis of the biofilm with change of the bacterial composition (Fig. 3). Current knowledge points to a symbiotic relationship between the oral microbiome and the host in health, contrasting with a dysbiosis of the microbial consortia driven by a sugar-frequent and acidic -pH environment in dental caries. ${ }^{18-20}$ In caries, continuous acid production from the metabolism of dietary carbohydrates favors the emergence of a highly acidogenic and aciduric microflora, enriched for Streptococcus mutans, other acid-tolerant streptococci, and Lactobacillus species. This selective process alters the $\mathrm{pH}$ homeostasis of supragingival biofilms and shifts the demineralizationremineralization equilibrium toward loss of tooth minerals.

Several studies support the observations that human supragingival dental plaque harbors a highly diverse bacterial community and that the microbiome of healthy tooth surfaces differs substantially from that found when there is evidence of caries activity. ${ }^{21-24}$ Changes in the microbial profile with the progressive stages of early childhood caries were observed when supragingival plaque of healthy tooth surfaces was compared with those of enamel and dentin carious lesions. ${ }^{7}$ In particular, plaque communities from dentin carious lesions of caries-active children showed a distinctive bacterial profile compared with the other communities. Moreover, communities from healthy tooth surfaces of caries-active children (CA-PF) were shown to be more similar to those from enamel carious lesions (CAE-PE and CA-PE) than to those of healthy teeth from caries-free children (CF-PF); suggesting that CA-PF sites appear to be at greater risk of caries development than CF-PF sites. This finding is concordant with previous risk factor studies for childhood caries ${ }^{25}$ and highlights the interconnectedness of plaque communities, in which these communities are part of a larger ecosystem where changes in the structure of 1 community may eventually affect others.

\section{MODULATION OF BIOFILM pH}

Carious lesions develop in tooth surfaces where there is an imbalance of the processes of acid and alkali production by supragingival biofilms. Because low $\mathrm{pH}$ is the main driving factor in the development of carious lesions, most efforts to identify an effective anticaries therapy have focused on targeting the acid-producing bacteria and their mechanisms of acid production. An expanding area of oral microbiology has been devoted to exploring microbial metabolic activities that help to neutralize biofilm $\mathrm{pH}$, and thus inhibit the caries process. One way to restore biofilm homeostasis is to equilibrate the acidity and alkalinity processes in order to maintain a neutral biofilm $\mathrm{pH}$. Physiologic factors that can counterbalance the acidification of biofilms include the clearance and buffering capacity of saliva and the metabolism of salivary substrates, such as urea and arginine, which generate alkali in the form of ammonia. In particular, ammonia production from arginine metabolism of oral bacteria inhibits tooth demineralization by neutralizing glycolytic acids and by favoring the growth of a desirable microflora that is compatible with dental health. ${ }^{26}$

\section{ARGININE IN CARIES PREVENTION: PREBIOTICS, PROBIOTICS, AND ORAL CARE FORMULATIONS}

L-arginine was identified as the main component responsible for the $\mathrm{pH}$-raising effect of saliva by early in vitro studies, ${ }^{27-29}$ and this amino acid is now receiving great attention 
because of its potential health benefits. Arginine is found free in saliva in micro-molar concentrations, and is also abundant in salivary peptides and proteins. ${ }^{30}$ Arginine enters the mouth through dietary components but is also naturally produced by the human body via protein turnover and de novo arginine synthesis from citrulline. Multiple pathways for arginine degradation have been described in microorganisms, and occasionally several of them are simultaneously present in the same organism. Among these pathways, the arginine deiminase system (ADS) is the most widespread anaerobic route for arginine degradation. ${ }^{31}$

In supragingival biofilms, arginine is metabolized mainly by ADS of certain oral bacteria to produce citrulline, ornithine, $\mathrm{CO}_{2}$, ATP, and ammonia (Fig. 4). Ammonia production via ADS results in cytoplasmic and environment $\mathrm{pH}$ rises and serves as a mechanism used by oral bacteria for

- $\quad$ Protection against acid killing

- $\quad$ Bioenergetic advantages, including the increase of $\mathrm{DpH}$ and synthesis of ATP

- $\quad$ Maintaining a neutral environmental $\mathrm{pH}$ that favors the persistence of ADSpositive (ADS+) bacteria while being competitive against caries pathogens ${ }^{11}$

The potential for arginine metabolism to prevent caries has been supported by compelling evidence from in vitro studies ${ }^{32-38}$ and clinical observations. ${ }^{13,30,34}$ Salivary levels of free arginine are strongly correlated with caries resistance. ${ }^{30}$ Plaque of caries-free individuals has higher $\mathrm{pH}$ values compared with plaque from caries-active individuals, ${ }^{34,37,39}$ and this difference has been correlated with elevated ammonia levels in caries-free subjects. ${ }^{34}$ The author's clinical studies revealed a positive correlation between caries activity and low arginolytic capacity of the supragingival microbial populations of adults and children. ${ }^{13,14}$ In brief, the author and colleagues measured the ADS activity of plaque collected from cariesfree tooth surfaces, enamel carious lesions, and dentin carious lesions of children who were either caries free or caries active. ${ }^{14}$ Mixed-model analysis evaluated if age, type of dentition, children's caries status, and plaque caries status could be used as predictors of ADS activity. A recent cohort study revealed the arginolytic potential of supragingival plaque populations of children over time in the context of caries status. ${ }^{40}$ As observed in previous crosssectional studies, plaque bacteria from caries-free children and caries-free tooth surfaces had consistently higher ADS activity compared with those from caries-active children and carious tooth surfaces during the 18 months of the study $(P<.0001) .{ }^{40}$

Numerous therapies have been proposed to target specific caries pathogens or indiscriminately eliminate oral biofilms (eg, xylitol, chlorhexidine, ${ }^{41}$ immunization, and bacterial replacement therapy). ${ }^{42}$ However, the effectiveness of these methods is yet to be recognized, and safety concerns have been raised with regards to their negative impact in the ecology of the oral microbiota. Novel therapies that seek to provide arginine as a substrate for ammonia production in oral biofilms may have high cost-effective potential for at-risk populations facing challenges accessing dental care. These promising approaches may include the use of arginine as prebiotic, selected $\mathrm{ADS}^{1}$ strains as probiotic, and/or introduction of arginine in oral care formulations. 
A technology designed to deliver arginine for ammonia production by plaque bacteria ${ }^{43}$ has been incorporated into toothpastes, mints, and chews. Over the last 10 years, clinical trials have been conducted to evaluate the anticaries efficacy of products containing this original arginine technology or other optimized arginine formulations with or without fluoride. ${ }^{44,45}$ A toothpaste containing $1.5 \%$ arginine, an insoluble calcium compound, and $1450 \mathrm{ppm}$ of fluoride was also shown to reduce caries increments in low- and moderate-risk children, to arrest and reverse carious lesions in children and adults, and to have superior caries benefits compared with a regular toothpaste containing $1450 \mathrm{ppm}$ of fluoride alone. ${ }^{46}$ Thus, the mechanisms of action of arginine appear to complement those of fluoride by directly influencing biofilm pH while impacting the composition of oral biofilms. Even though the supplementation of arginine to oral biofilms can be effective against caries, the long-term impact of these novel arginine-based technologies on oral health and etiology of other oral diseases such as periodontal disease remains to be investigated.

\section{ORAL PROBIOTICS FOR CARIES CONTROL}

The use of orally administered probiotic species is gaining popularity as a strategy for maintaining oral health. Probiotics are defined as viable microorganisms that confer health benefits when administered in sufficient doses. There is a long history behind the use of probiotics for prevention and treatment of many medical conditions. Probiotics are an alternative to pharmaceutical management, notwithstanding the constant debates on their beneficial versus adverse effects. The increased popularity of using probiotic bacteria to improve gastrointestinal health has prompted interest in the value of this approach for oral applications. Consequently, much attention has been given lately to the role of probiotics in preventing caries, and the administration of different strains of Lactobacilli and/or Bifidobacteria has been tested to battle cariogenic bacteria. ${ }^{47}$ The mechanisms of action of probiotics are thought to combine local and systemic effects including adhesion, coaggregation, growth inhibition, production of organic acids and bacteriocins, and immune modulation, ${ }^{48}$ with the ultimate goal of displacing and perhaps replacing pathogens. These mechanisms may vary according to the specific bacterial strain or combinations of strains used, the delivery system, and the stage of the disease process in which the probiotic is administered.

Several studies have demonstrated successful in vivo and in vitro application of dairy product-derived oral probiotic species, predominantly lactobacilli, highlighting the potential of probiotics in oral health care. Select strains of lactobacilli inhibit growth and biofilm formation of caries-associated species $S$. mutans and Candida albicans in culture. ${ }^{49}$ In vitro biofilm growth assays demonstrated that strains of Lactobacillus, Lactococcus, and Streptococcus can integrate into saliva-derived or defined-species biofilms and are maintained in the biofilms over several days. ${ }^{48,50,51}$ However, an in vivo study reported that no probiotic lactobacilli were detected in dental plaque of individuals after 8-day treatment with fermented milk, ${ }^{52}$ so the method by which such probiotic strains act on the biofilm in vivo needs further investigation.

Although the potential of using probiotics to manage caries appears to be high, the probiotic strains tested for oral health are, at the moment, microorganisms used mainly for 
gastrointestinal benefits, and they are likely not to adapt well to the unique environmental conditions and complex ecology of oral biofilms. ${ }^{47}$ These probiotic strains do not seem to colonize the oral cavity permanently, which may be related to the number of receptors in the dental pellicle available for colonization of these nonoral strains compared with receptors for indigenous oral bacteria. ${ }^{53}$ It has been proposed that naturally occurring oral strains with diminished cariogenic potential and desirable antagonistic properties on cariogenic bacteria may be proven successful as probiotic therapies for caries. ${ }^{54}$ These oral species have the advantage of being adapted to growth in the mouth and the oral biofilm, and they may offer more sustainable and longer-term probiotic benefits than species from external sources like dairy products. In particular, several Streptococcus species, including Streptococcus gordonii, Streptococcus sanguinis, and Streptococcus salivarius are associated with oral health, and $S$ salivarius $\mathrm{K} 12$ has been adapted as a probiotic for pharyngitis/tonsillitis, halitosis, and otitis media. In this context, Streptococcus A12 and other arginolytic clinical strains with constitutionally high ADS-expressing phenotypes and those capable of expressing ADS under conditions known to cause caries (eg, sugar availability and acidic environment) are being tested as probiotic strains for caries prevention.

\section{PREBIOTICS FOR CARIES CONTROL}

Prebiotics are defined as fermented food ingredients that can change the composition and/or activity of the resident microflora and confer benefits upon host well-being and health. ${ }^{55}$

The concept of prebiotic has attracted and inspired research in many areas of nutrition and medical sciences. Several studies have shown that dietary consumption of certain food products can selectively modulate the indigenous composition of the gut microbiota. ${ }^{56}$ However, sugars and dietary fiber, which are considered to be prebiotics for intestinal lactic acid bacteria, are not suited for the oral environment. Some potential oral prebiotics such as xylitol, xylose, and arabinose could suppress the growth of $S$. mutans, but they could also promote the growth of some lactobacilli strains. Given the lack of some suitable oral prebiotics, there several studies attempting to identify new prebiotics. As a natural dietary supplement, arginine has been extensively researched in medicine primarily to improve the symptoms of cardiovascular disease. ${ }^{57}$ This is because arginine is a precursor of nitric oxide (NO), which plays important roles in vasodilatation, bacterial challenge and cytokine stimulation, regulation of mineralized tissue function, neurotransmission, and platelet aggregation. ${ }^{58}$

Recent in vitro studies have shown that providing L-arginine to supragingival biofilms disrupts the process of biofilm matrix assembly and the microbial interactions that are associated with the development of cariogenic biofilms, ${ }^{59}$ and also confers biofilm $\mathrm{pH}$ homeostasis. ${ }^{60}$ Interestingly, dietary questionnaires used in the author's clinical studies revealed that a group of caries-free participants presenting extremely high levels of plaque ADS activity reported high consumption of protein bars or protein shakes, which are major sources of arginine (Nascimento et al, unpublished data, 2019). Although arginine supplementation may have a positive impact in supragingival biofilms, NO generated from arginine metabolism may be involved in the pathogenesis of periodontitis ${ }^{61}$ Clearly, longterm randomized clinical trials are needed to determine whether dietary supplementation of arginine could be advantageous for oral health. Besides, it is critical to determine the correct 
supplementation level of dietary arginine before this amino acid can be used as a prebiotic approach for caries intervention.

\section{ANTIBIOFILM TECHNOLOGIES USING PH AND OTHER ENVIRONMENTAL STIMULI}

Triggering antibiofilm activity in response to pathogenic microenvironments could specifically target the development of cariogenic biofilms. Treating cariogenic biofilms is puzzling, as the organisms are often embedded in a protective, highly adherent, cohesive, and difficult to remove EPS matrix. Conventional antimicrobial modalities are limited in addressing the biochemical properties of the biofilm matrix, whereas upcoming therapeutic strategies are being developed to specifically target the microenvironments of the matrix and the embedded bacteria with minimal cytotoxicity to surrounding tissues. Nanotechnologies that can penetrate biofilms and damage the matrix may enhance antibacterial efficacy and minimize initiation of drug or antibacterial resistance.

Functional polymeric nanostructures (PNs) were developed for enhanced drug delivery when triggered by acidic $\mathrm{pH}$ values. ${ }^{62}$ These nanostructures are formed from diblock copolymers and 2-propylacrylic acid that self-assemble into cationic nanoparticles, and they have adsorption affinities to salivary pellicle and EPS-coated apatitic surfaces because of strong electrostatic interaction. ${ }^{62}$ In addition, the nanoparticles endure core destabilization and drug release in response to changes in $\mathrm{pH}$, triggered by biofilm acidification.

Another promising approach employs $\mathrm{pH}$-responsive catalytic inorganic nanoparticles (CATNPs) with antibiofilm and anticaries properties. ${ }^{63}$ Nanoparticles containing biocompatible iron-oxide $\left(\mathrm{Fe}_{3} \mathrm{O}_{4}\right)$ with peroxidase-like activity were developed to catalyze $\mathrm{H}_{2} \mathrm{O}_{2}$ in a pHdependent manner (eg, greater catalytic activity at low $\mathrm{pH}$ and no activity at neutral $\mathrm{pH}$ ). ${ }^{64}$ In situ studies showed that under acidic $\mathrm{pH}$, the catalytic nanoparticles can generate free radicals from $\mathrm{H}_{2} \mathrm{O}_{2}$ that concurrently damage the EPS matrix and kill the biofilm bacteria within 5 minutes. ${ }^{64}$ CAT-NPs were also shown to decrease demineralization of apatite disks in vitro. CAT-NPs in combination with $\mathrm{H}_{2} \mathrm{O}_{2}$ were tested in vivo as 1-minute topical daily treatments, and the results were shown to decrease caries development without harmful effects to soft tissues. ${ }^{64}$ Further toxicity studies are needed to investigate the long-term effects of topical applications, but the combination of CAT-NPs and $\mathrm{H}_{2} \mathrm{O}_{2}$ has clinical potential.

\section{APPROACHES TO DISRUPT BIOFILMS}

Other recent approaches have emerged to disrupt the biofilm microbial composition and the microenvironment. ${ }^{65}$ An $S$. mutans-specific targeting approach was developed using synthetic antimicrobial peptide (AMP) consisting of dual-functionally independent moieties (named C16G2), a broad-spectrum, novispirin-derived AMP killing region (G2) attached to an $S$. mutans-specific peptide pheromone that provides targeting specificity $(\mathrm{C} 16) .{ }^{65}$ Selective killing of $S$. mutans was achieved after increased rate of G2 accumulation on the bacterial surface. In this study, the population of $S$. mutans was reduced from multispecies biofilm communities, while the abundance of commensal streptococci, including 
Streptococcus mitis, Streptococcus oralis, and $S$ sanguinis were increased. ${ }^{65}$ An AMP containing an $S$. mutans-targeting domain to the ComC signaling peptide fused with a killing domain composed of broad-spectrum AMP pleurocidin was also demonstrated to enhance specificity against $S$. mutans while maintaining $S$ sanguinis or $S$ gordonii cells in vitro. ${ }^{66}$ This is another example of a targeted killing approach, which may remove specific pathogens from cariogenic biofilms to promote a healthy-like microbiome. However, and as mentioned for all approaches cited previously, in vivo studies are necessary to better understand the anticaries mechanisms and efficacy as well as to address safety concerns.

Biopharmaceuticals made via plant-chloroplast technology are also being considered as a biofilm-disrupting approach for caries control. The US Food and Drug Administration (FDA) approval of plant-produced protein drugs supports the clinical advancement of this type pf technology. For example, an approach using plant-made antimicrobial peptide (PMAMP)-Protegrin (PG1) was also developed for topical use to control biofilms. ${ }^{67,68}$ PMAMP-PG1 was shown to rapidly killed $S$. mutans and impaired biofilm formation following a single topical application of the tooth-mimetic apatite surface. The combined use of PG1 with 2 EPS-degrading enzymes, dextranase and mutanase, was capable of digesting biofilm matrix and facilitating peptide access into the biofilm structure in addition to killing bacterial clusters. ${ }^{68,69}$

\section{WHERE ARE WE HEADING?}

Future research precisely identifying the key oral microbiota in health and disease will contribute to the advancement of more effective tools for modulation of oral biofilms. Even though the healthy oral microbiome appears to be more stable than those of other body niches like the gut, there is evidence for a substantial degree of within-individual variability in the oral microbiome. ${ }^{70,71}$ Genetic diversity and complexities in the adaptive strategies of oral bacteria to fluctuating biofilm conditions diminish the utility of taxa-level correlation of the microbiome with health especially, but also with caries and periodontal disease. The relevant questions may be answered by elucidating what the microbes are doing, rather than focusing primarily on what is performing those actions. ${ }^{20}$ Also deserving more attention are the microbial interactions with the host (eg, adhesion mechanisms between microbes and salivary proteins $)^{72}$ and the recognition patterns with the oral immune system. ${ }^{73}$ Future directions should focus on achieving maximal efficacy and targeting specificity with minimal toxicity and long-term therapeutic effects. These, along with enhanced drug delivery/activation within pathogenic microenvironments, may enlighten the way for an effective therapeutic strategy with high precision against cariogenic biofilms.

\section{SUMMARY}

Studies of the oral microbiome may hold the answers for understanding human diseases even beyond the oral cavity. Several emerging strategies for modulation of supragingival oral biofilms have been explored and are being successfully developed and tested in vitro. Still, clinical studies are needed to investigate the efficacy and safety of these approaches for caries prevention and control. Future microbiome and metagenome analyses will certainly 
contribute to the development of more effective therapeutic and diagnostic techniques and ultimately to personalized medicine and personalized dentistry.

\section{Disclosure Statement:}

Some of the author's research work cited in this article has been supported by the National Institute of Dental and Craniofacial Research and by Colgate-Palmolive.

\section{REFERENCES}

1. Cahill TJ, Harrison JL, Jewell P, et al. Antibiotic prophylaxis for infective endocarditis: a systematic review and meta-analysis. Heart 2017;103(12):937-44. [PubMed: 28213367]

2. Kriebel K, Hieke C, Muller-Hilke B, et al. Oral biofilms from symbiotic to pathogenic interactions and associated disease -connection of periodontitis and rheumatic arthritis by peptidylarginine deiminase. Front Microbiol 2018;9:53. [PubMed: 29441048]

3. Proctor LM. The National Institutes of Health human microbiome project. Semin Fetal Neonatal Med 2016;21(6):368-72. [PubMed: 27350143]

4. Turnbaugh PJ, Ley RE, Hamady M, et al. The human microbiome project. Nature 2007;449(7164): 804-10. [PubMed: 17943116]

5. Gomez A, Nelson KE. The oral microbiome of children: development, disease, and implications beyond oral health. Microb Ecol 2017;73(2):492-503. [PubMed: 27628595]

6. Dewhirst FE, Chen T, Izard J, et al. The human oral microbiome. J Bacteriol 2010; 192(19):500217. [PubMed: 20656903]

7. Richards VP, Alvarez AJ, Luce AR, et al. Microbiomes of site-specific dental plaques from children with different caries status. Infect Immun 2017;85(8) [pii: e00106-17]. [PubMed: 28507066]

8. Jakubovics NS. Saliva as the sole nutritional source in the development of multispecies communities in dental plaque. Microbiol Spectr 2015;3(3):1-11.

9. Wei GX, van der Hoeven JS, Smalley JW, et al. Proteolysis and utilization of albumin by enrichment cultures of subgingival microbiota. Oral Microbiol Immunol 1999;14(6):348-51. [PubMed: 10895689]

10. Burne RA, Zeng L, Ahn SJ, et al. Progress dissecting the oral microbiome in caries and health. Adv Dent Res 2012;24(2):77-80. [PubMed: 22899685]

11. Burne RA, Marquis RE. Alkali production by oral bacteria and protection against dental caries. FEMS Microbiol Lett 2000;193(1):1-6. [PubMed: 11094270]

12. Marsh PD, Takahashi N, Nyvad B. Biofilms in caries development In: Fejerskov O, Nyvad B, Kidd E, editors. Dental caries: the disease and its clinical management. 3rd edition Wiley-Blackwell; 2015 p. 107-31.

13. Nascimento MM, Gordan VV, Garvan CW, et al. Correlations of oral bacterial arginine and urea catabolism with caries experience. Oral Microbiol Immunol 2009; 24(2):89-95. [PubMed: 19239634]

14. Nascimento MM, Liu Y, Kalra R, et al. Oral arginine metabolism may decrease the risk for dental caries in children. J Dent Res 2013;92(7):604-8. [PubMed: 23640952]

15. Mark Welch JL, Rossetti BJ, Rieken CW, et al. Biogeography of a human oral microbiome at the micron scale. Proc Natl Acad Sci U S A 2016;113(6):E791-800. [PubMed: 26811460]

16. Wade W, Thompson H, Rybalka A. Uncultured members of the oral microbiome. J Calif Dent Assoc 2016;44(7):447-56. [PubMed: 27514156]

17. Marsh PD. Ecological events in oral health and disease: new opportunities for prevention and disease control? J Calif Dent Assoc 2017;45(10):525-37.

18. Marsh PD. Dental plaque as a biofilm and a microbial community - implications for health and disease. BMC Oral Health 2006;6(Suppl 1):S14. [PubMed: 16934115]

19. Nascimento MM, Zaura E, Mira A, et al. Second era of OMICS in caries research: moving past the phase of disillusionment. J Dent Res 2017;96(7):733-40, 22034517701902. [PubMed: 28384412] 
20. Takahashi N Oral microbiome metabolism: from "who are they?" to "what are they doing?". J Dent Res 2015;94(12):1628-37. [PubMed: 26377570]

21. Aas JA, Griffen AL, Dardis SR, et al. Bacteria of dental caries in primary and permanent teeth in children and young adults. J Clin Microbiol 2008;46(4):1407-17. [PubMed: 18216213]

22. Belda-Ferre P, Alcaraz LD, Cabrera-Rubio R, et al. The oral metagenome in health and disease. ISME J 2012;6(1):46-56. [PubMed: 21716308]

23. Gross EL, Beall CJ, Kutsch SR, et al. Beyond Streptococcus mutans: dental caries onset linked to multiple species by 16S rRNA community analysis. PLoS One 2012;7(10):e47722. [PubMed: 23091642]

24. Gross EL, Leys EJ, Gasparovich SR, et al. Bacterial 16S sequence analysis of severe caries in young permanent teeth. J Clin Microbiol 2010;48(11):4121-8. [PubMed: 20826648]

25. Lee HJ, Kim JB, Jin BH, et al. Risk factors for dental caries in childhood: a five-year survival analysis. Community Dent Oral Epidemiol 2015;43(2):163-71. [PubMed: 25401281]

26. Nascimento MM, Burne RA. Caries prevention by arginine metabolism in oral biofilms: translating science into clinical success. Curr Oral Health Rep 2014;1(1): 79-85.

27. Kanapka JA, Kleinberg I. Catabolism of arginine by the mixed bacteria in human salivary sediment under conditions of low and high glucose concentration. Arch Oral Biol 1983;28(11):1007-15. [PubMed: 6419713]

28. Kleinberg I, Kanapka JA, Chatterjee R, et al. Metabolism of nitrogen by the oral mixed bacteria. London: Information Retrieval; 1979.

29. Wijeyeweera RL, Kleinberg I. Acid-base $\mathrm{pH}$ curves in vitro with mixtures of pure cultures of human oral microorganisms. Arch Oral Biol 1989;34(1):55-64. [PubMed: 2675801]

30. Van Wuyckhuyse BC, Perinpanayagam HE, Bevacqua D, et al. Association of free arginine and lysine concentrations in human parotid saliva with caries experience. J Dent Res 1995;74(2):68690. [PubMed: 7722066]

31. Zuniga M, Perez G, Gonzalez-Candelas F. Evolution of arginine deiminase (ADI) pathway genes. Mol Phylogenet Evol 2002;25(3):429-44. [PubMed: 12450748]

32. Imfeld T, Birkhed D, Lingstrom P. Effect of urea in sugar-free chewing gums on pH recovery in human dental plaque evaluated with three different methods. Caries Res 1995;29(3):172-80. [PubMed: 7621491]

33. Kleinberg I. Prevention and dental caries. J Prev Dent 1978;5(3):9-17. [PubMed: 36479]

34. Margolis HC, Duckworth JH, Moreno EC. Composition of pooled resting plaque fluid from cariesfree and caries-susceptible individuals. J Dent Res 1988; 67(12):1468-75. [PubMed: 3198844]

35. Sissons CH, Cutress TW. pH changes during simultaneous metabolism of urea and carbohydrate by human salivary bacteria in vitro. Arch Oral Biol 1988; 33(8):579-87. [PubMed: 3254127]

36. Kleinberg I A mixed-bacteria ecological approach to understanding the role of the oral bacteria in dental caries causation: an alternative to Streptococcus mutans and the specific-plaque hypothesis. Crit Rev Oral Biol Med 2002;13(2): 108-25. [PubMed: 12097354]

37. Stephan RM. Intra-oral hydrogen-ion concentration associated with dental caries activity. J Dent Res 1944;23:257-66.

38. Turtola LO, Luoma H. Plaque $\mathrm{pH}$ in caries-active and inactive subjects modified by sucrose and fluoride, with and without bicarbonate-phosphate. Scand J Dent Res 1972;80(4):334-43. [PubMed: 4506735]

39. Rosen S, Weisenstein PR. The effect of sugar solutions on $\mathrm{pH}$ of dental plaques from cariessusceptible and caries-free individuals. J Dent Res 1965;44(5): 845-9. [PubMed: 4378487]

40. Nascimento MM, Alvarez AJ, Huang X, et al. Arginine metabolism in supragingival oral biofilms as a potential predictor of caries risk. JDR Clin Trans Res 2019; 4(3):262-70, 2380084419834234. [PubMed: 31039043]

41. James P, Parnell C, Whelton $\mathrm{H}$. The caries-preventive effect of chlorhexidine varnish in children and adolescents: a systematic review. Caries Res 2010;44(4): 333-40. [PubMed: 20606432]

42. Hillman JD. Genetically modified Streptococcus mutans for the prevention of dental caries. Antonie Van Leeuwenhoek 2002;82(1-4):361-6. [PubMed: 12369203] 
43. Kleinberg I A new saliva-based anti-caries composition. Dent Today 1999;18: 98-103. [PubMed: 10765818]

44. Acevedo AM, Machado C, Rivera LE, et al. The inhibitory effect of an arginine bicarbonate/ calcium carbonate CaviStat-containing dentifrice on the development of dental caries in Venezuelan school children. J Clin Dent 2005;16(3):63-70. [PubMed: 16305004]

45. Acevedo AM, Montero M, Rojas-Sanchez F, et al. Clinical evaluation of the ability of CaviStat in a mint confection to inhibit the development of dental caries in children. J Clin Dent 2008;19(1):18. [PubMed: 18500152]

46. Kraivaphan P, Amornchat C, Triratana T, et al. Two-year caries clinical study of the efficacy of novel dentifrices containing $1.5 \%$ arginine, an insoluble calcium compound and 1,450 ppm fluoride. Caries Res 2013;47(6):582-90. [PubMed: 23988908]

47. Cagetti MG, Mastroberardino S, Milia E, et al. The use of probiotic strains in caries prevention: a systematic review. Nutrients 2013;5(7):2530-50. [PubMed: 23857225]

48. Devine DA, Marsh PD. Prospects for the development of probiotics and prebiotics for oral applications. J Oral Microbiol 2009;1:1-11.

49. Hasslof P, West CE, Videhult FK, et al. Early intervention with probiotic Lactobacillus paracasei F19 has no long-term effect on caries experience. Caries Res 2013;47(6):559-65. [PubMed: 23838478]

50. Twetman S, Keller MK. Probiotics for caries prevention and control. Adv Dent Res 2012;24(2):98102. [PubMed: 22899689]

51. Jindal G, Pandey RK, Agarwal J, et al. A comparative evaluation of probiotics on salivary mutans streptococci counts in Indian children. Eur Arch Paediatr Dent 2011;12(4):211-5. [PubMed: 21806906]

52. Ravn I, Dige I, Meyer RL, et al. Colonization of the oral cavity by probiotic bacteria. Caries Res 2012;46(2):107-12. [PubMed: 22398457]

53. Comelli EM, Guggenheim B, Stingele F, et al. Selection of dairy bacterial strains as probiotics for oral health. Eur J Oral Sci 2002;110(3):218-24. [PubMed: 12120707]

54. Hillman JD, McDonell E, Cramm T, et al. A spontaneous lactate dehydrogenase deficient mutant of Streptococcus rattus for use as a probiotic in the prevention of dental caries. J Appl Microbiol 2009;107(5):1551-8. [PubMed: 19426263]

55. Roberfroid M Prebiotics: the concept revisited. J Nutr 2007;137(3 Suppl 2): 830S-7S. [PubMed: 17311983]

56. Roberfroid M, Gibson GR, Hoyles L, et al. Prebiotic effects: metabolic and health benefits. Br J Nutr 2010;104(Suppl 2):S1-63.

57. Lorin J, Zeller M, Guilland JC, et al. Arginine and nitric oxide synthase: regulatory mechanisms and cardiovascular aspects. Mol Nutr Food Res 2014;58(1):101-16. [PubMed: 23740826]

58. Morris SM Jr. Arginine metabolism revisited. J Nutr 2016;146(12):2579S-86S. [PubMed: 27934648]

59. He J, Hwang G, Liu Y, et al. L-arginine modifies the exopolysaccharides matrix and thwarts Streptococcus mutans outgrowth within mixed-species oral biofilms. J Bacteriol 2016;198(19): 2651-61. [PubMed: 27161116]

60. Agnello M, Cen L, Tran NC, et al. Arginine improves $\mathrm{pH}$ homeostasis via metabolism and microbiome modulation. J Dent Res 2017;96(8):924-30. [PubMed: 28486080]

61. Parwani SR, Parwani RN. Nitric oxide and inflammatory periodontal disease. Gen Dent 2015;63(2):34-40. [PubMed: 25734284]

62. Horev B, Klein MI, Hwang G, et al. pH-activated nanoparticles for controlled topical delivery of farnesol to disrupt oral biofilm virulence. ACS Nano 2015; 9(3):2390-404. [PubMed: 25661192]

63. Liu Y, Ren Z, Hwang G, et al. Therapeutic strategies targeting cariogenic biofilm microenvironment. Adv Dent Res 2018;29(1):86-92. [PubMed: 29355421]

64. Gao L, Liu Y, Kim D, et al. Nanocatalysts promote Streptococcus mutans biofilm matrix degradation and enhance bacterial killing to suppress dental caries in vivo. Biomaterials 2016;101:272-84. [PubMed: 27294544] 
65. Guo L, McLean JS, Yang Y, et al. Precision-guided antimicrobial peptide as a targeted modulator of human microbial ecology. Proc Natl Acad Sci U S A 2015; 112(24):7569-74. [PubMed: 26034276]

66. Mai J, Tian XL, Gallant JW, et al. A novel target-specific, salt-resistant antimicrobial peptide against the cariogenic pathogen Streptococcus mutans. Antimicrob Agents Chemother 2011;55(11):5205-13. [PubMed: 21844316]

67. Liu L, Hao T, Xie Z, et al. Genome mining unveils widespread natural product biosynthetic capacity in human oral microbe Streptococcus mutans. Sci Rep 2016;6:37479. [PubMed: 27869143]

68. Liu Y, Kamesh AC, Xiao Y, et al. Topical delivery of low-cost protein drug candidates made in chloroplasts for biofilm disruption and uptake by oral epithelial cells. Biomaterials 2016;105:15666. [PubMed: 27521618]

69. Kwon KC, Daniell H. Low-cost oral delivery of protein drugs bioencapsulated in plant cells. Plant Biotechnol J 2015;13(8):1017-22. [PubMed: 26333301]

70. Caporaso JG, Lauber CL, Costello EK, et al. Moving pictures of the human microbiome. Genome Biol 2011;12(5):R50. [PubMed: 21624126]

71. Turnbaugh PJ, Hamady M, Yatsunenko T, et al. A core gut microbiome in obese and lean twins. Nature 2009;457(7228):480-4. [PubMed: 19043404]

72. Nobbs AH, Jenkinson HF, Jakubovics NS. Stick to your gums: mechanisms of oral microbial adherence. J Dent Res 2011;90(11):1271-8. [PubMed: 21335541]

73. Simon-Soro A, Mira A. Solving the etiology of dental caries. Trends Microbiol 2015;23(2):76-82. [PubMed: 25435135] 


\section{KEY POINTS}

- The $\mathrm{pH}$ and carbohydrate availability are key environmental factors affecting the physiology, ecology, and pathogenicity of oral biofilms colonizing teeth.

- Maintenance of oral health depends on the homeostasis of a consortium of commensal bacteria, such as that found in healthy-associated supragingival oral biofilms.

- $\quad$ Novel anticaries strategies include the modulation of the biofilm $\mathrm{pH}$ via arginine metabolism, nanotechnologies using acid-activated agents, oral probiotics and prebiotics, species-specific antimicrobial peptides targeting cariogenic pathogens, and other antibiofilm-specific approaches. 

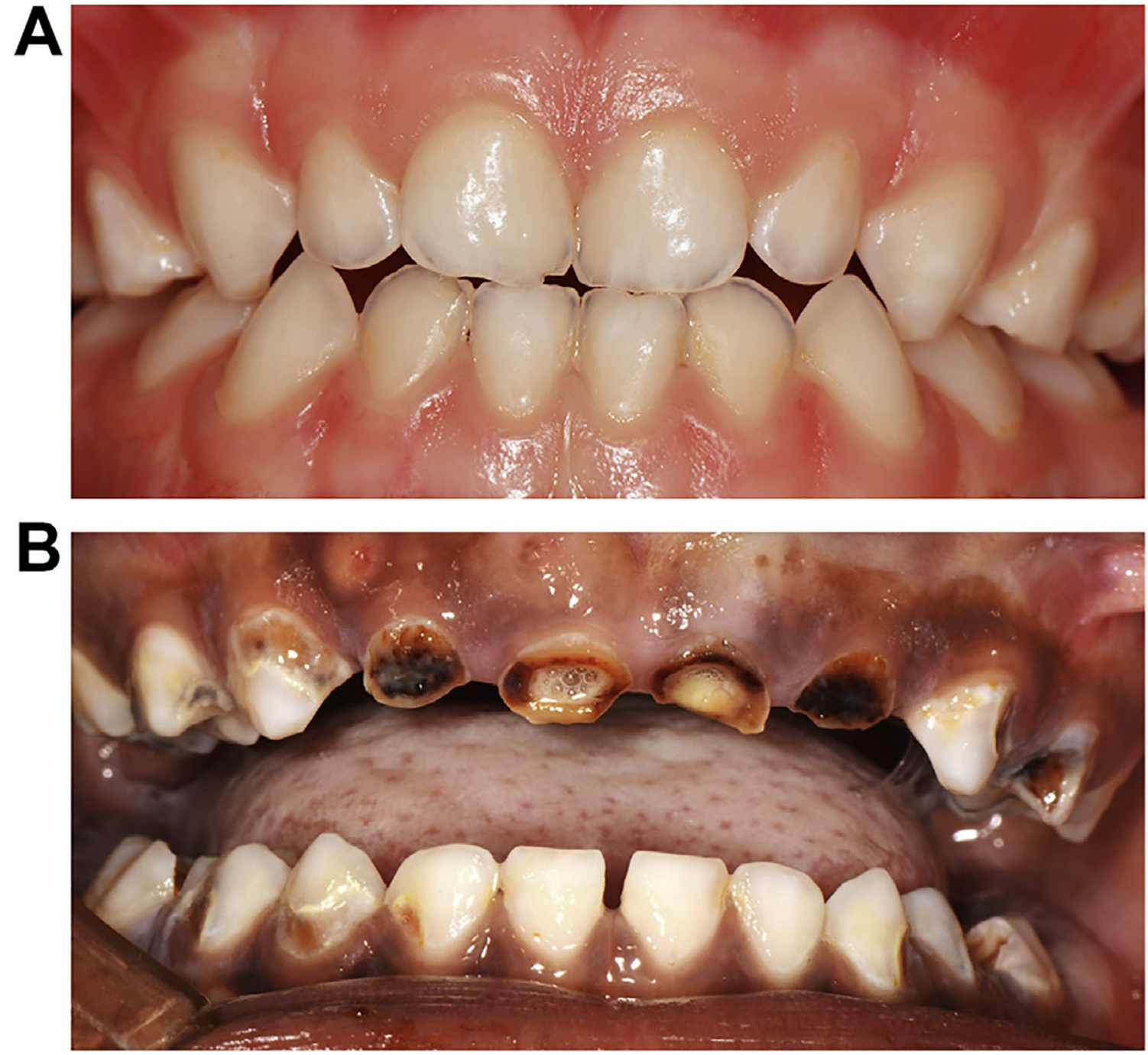

Fig. 1.

( $A$ ) Child presenting a healthy oral cavity. (B) Child presenting early childhood dental caries (ECC). (Courtesy of Marcelle M. Nascimento, DDS, MS, PhD, Gainesville, FL.) 

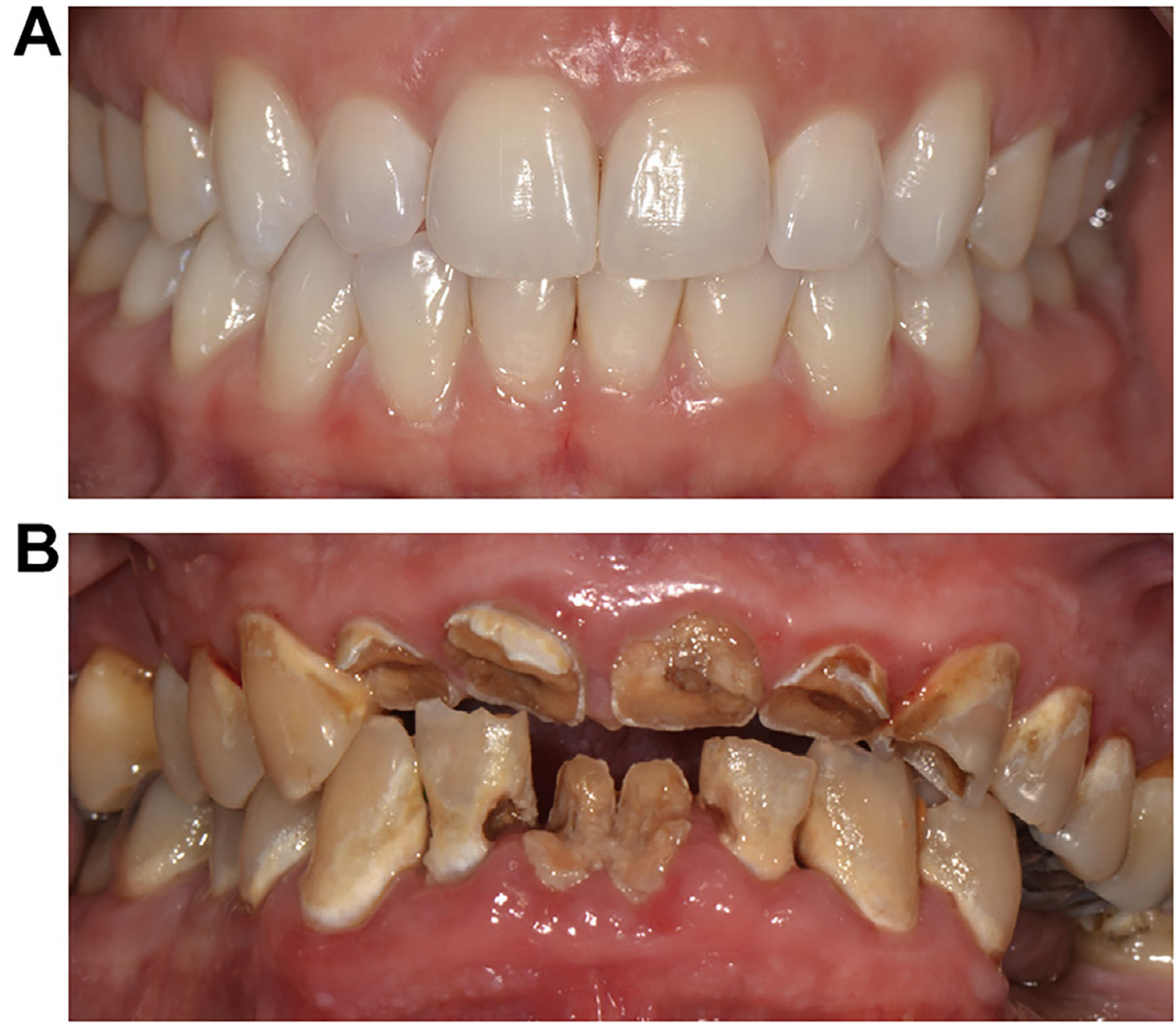

Fig. 2.

( $A$ ) Adult presenting a healthy oral cavity. $(B)$ Adult presenting both dental caries and periodontal diseases. (Courtesy of Marcelle M. Nascimento, DDS, MS, PhD, Gainesville, FL.) 

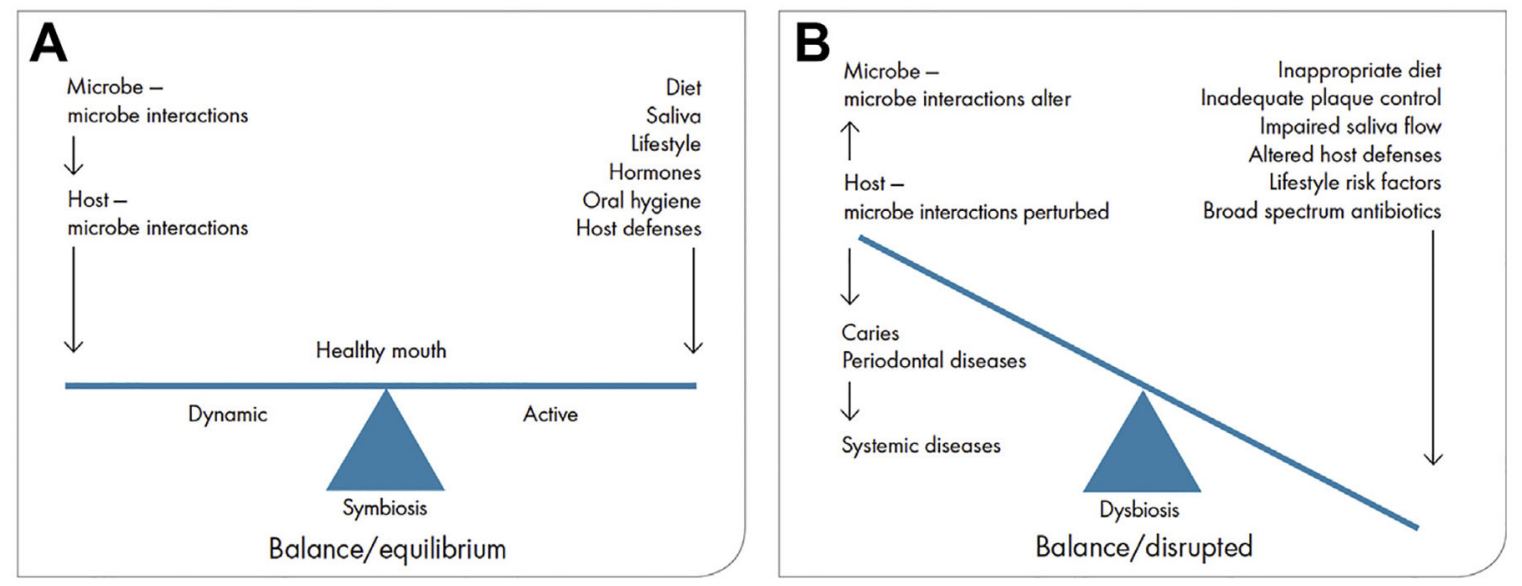

Fig. 3.

A schematic representation of the dynamic relationship between the oral microbiome and the host environment in health and disease. $(A)$ In health, a natural balance is maintained between host and environmental factors that results in a stable microbiota (ie, microbemicrobe interactions are in equilibrium), and a beneficial relationship with host tissues is established. This symbiotic relationship is susceptible to change. (B) A major change in the oral environment or lifestyle of the host can upset the delicate balance that exists among the many species that make up the oral microbiota. Previously minor components can become more competitive and predominate, which disrupts the previously symbiotic relationship with the host and increases the risk of disease. (Reprinted with permission from the California Dental Association, copyright October 2017.) ${ }^{17}$ 


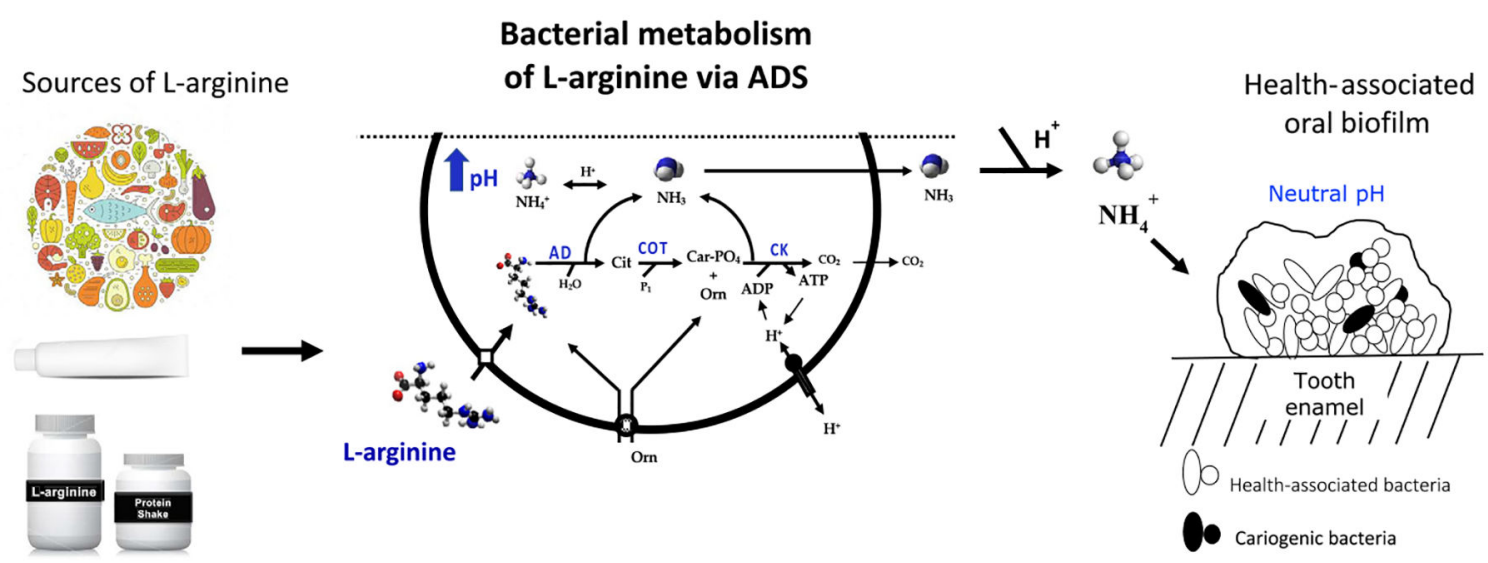

Fig. 4.

Bacterial arginine metabolism via the ADS (arginine deiminase system), which is a 3enzyme pathway (AD, arginine deiminase; COT, catabolic ornithine transcarbamylase; and CK, catabolic carbamate kinase). The major sources of arginine (L-arginine) for oral bacteria are: diet (fruits, vegetables, and animal sources), arginine as salivary peptides, de novo arginine synthesis from citrulline via protein turnover by the human body, use of oral care products (eg, toothpastes) and mints, and arginine supplements (eg, L-arginine capsules and protein shakes). Ammonia production via ADS results in increased $\mathrm{pH}$ values of the bacterial cytoplasmic and supragingival oral biofilms. 